\title{
Prevalence of Mycotoxins and Their Consequences on Human Health
}

\author{
Oluwadara Pelumi Omotayo ${ }^{1}$, Abiodun Olusola Omotayo ${ }^{2}$, Mulunda Mwanza ${ }^{3}$ \\ and Olubukola Oluranti Babalola ${ }^{4}$ \\ ${ }^{1}$ Department of Biological Sciences, Faculty of Natural and Agricultural Science, North-West University, Mmabatho, \\ South Africa \\ ${ }^{2}$ Food Security and Safety Niche, Faculty of Natural and Agricultural Science, North-West University, Mafikeng \\ Campus, Mmabatho, South Africa \\ ${ }^{3}$ Department of Animal Health, Faculty of Natural and Agricultural Science, North-West University, Mmabatho, \\ South Africa \\ ${ }^{4}$ Food Security and Safety Niche, Faculty of Natural and Agricultural Sciences, North-West University, Mmabatho, \\ South Africa
}

\begin{abstract}
Mycotoxin contamination is a global phenomenon and causes a wide array of negative effects and other complications. This study focused on commonly found mycotoxins in Africa and the possible means of prevention or reduction of their contaminating effects. Mycotoxins are secondary metabolites of mold and fungi; they are generally toxic to living organisms. Hundreds of mycotoxins have been identified thus far, with some, such as aflatoxins, ochratoxins, trichothecenes, zearalenone, fumonisins, and patulin, considered agro-economically important. Several factors contribute to the presence of mycotoxins in food, such as climatic conditions, pest infestation, and poor harvest and storage practices. Exposure to mycotoxins, which occurs mostly by ingestion, leads to various diseases, such as mycotoxicoses and mycoses that may eventually result in death. In light of this, this review of relevant literature focuses on mycotoxin contamination, as well as various methods for the prevention and control of their prevalence, to avert its debilitating consequences on human health. Clear evidence of mycotoxin contamination is present in Africa, and it was therefore recommended that adequate prevention and control of these toxic substances in our food system should be encouraged and that appropriate measures must be taken to ensure food safety as well as the enhanced or long-lifespan of the African populace. Governments, research institutions, and non-governmental organizations should tailor the limited resources available to tackle mycotoxin prevalence, as these will offer the best prospects for successful development of a sustainable food system in Africa.
\end{abstract}

Key words: Mycotoxin, Contamination, Prevalence, Toxic, Food safety

\section{INTRODUCTION}

Over the years, mycotoxin contamination of food, feed, and agricultural products has emerged as an issue of seri-

Correspondence to: Oluwadara Pelumi Omotayo, Department of Biological Sciences, Faculty of Natural and Agricultural Science, NorthWest University, Private Bag X2046, Mmabatho 2735, South Africa E-mail: alamuoluwadara@gmail.com

This is an Open-Access article distributed under the terms of the Creative Commons Attribution Non-Commercial License (http:// creativecommons.org/licenses/by-nc/3.0) which permits unrestricted non-commercial use, distribution, and reproduction in any medium, provided the original work is properly cited. ous concern, as these toxic substances in (1) may cause different types of poisoning and, consequently, diverse health problems (from acute to chronic problems) in both animals and humans (1). Mycotoxins are natural contaminants of food and agricultural products all over the world (2). These secondary metabolites are produced by toxigenic fungi (2), which are classified as species of fungi that can produce one or more mycotoxins. Mycotoxins can be produced by multiple fungal species (1); for example, aflatoxins and ochratoxins are produced by more than one fungal species (2), and this contributes to the yearround presence of mycotoxins.

There are many different mycotoxins; apart from the 
aflatoxins and ochratoxins mentioned previously, other examples include fumonisins, zearalenone, trichothecenes, and patulin. Some of these have been classified by the world health organization (WHO) as human carcinogens. Most mycotoxins currently known are grouped based on their toxic activity under chronic conditions, into mutagenic, carcinogenic, or teratogenic mycotoxins. For example, aflatoxins that occur naturally are classified as human carcinogens (Group 1); ochratoxins and fumonisin are classified as possible human carcinogens (Group 2B), whereas trichothecenes and zearaleone are not recognized as human carcinogens (Group 3) (3). However, virtually all mycotoxins can cause one or more major health problems. In addition, some of these mycotoxins suppress the immune system $(4,5)$, thereby exposing the consumer to health threats.

Moreover, the effect of mycotoxins on human health can be influenced by age, sex, weight, diet, exposure to infectious agents, quantity of toxins exposed, and the presence of other mycotoxins (synergistic effects) and pharmacologically active substances (4-6). For example, in humans, the rate at which exposure to mycotoxins occurs will affect a young person or an infant to a greater degree than an adult (6); in addition, the quantity of exposure is a major determinant of the degree of toxicity to the consumer. However, the severity of poisoning by these toxins can be complicated by factors such as vitamin deficiency, low calorie intake, alcohol abuse, or the presence of an infectious disease (5). In conclusion, over 300 mycotoxins have been identified worldwide (6). The increase in mycotoxin contamination in developing nations, predominantly Africa, is occurring at an alarming rate owing to poor implementation of thorough food scrutinizing policies that ensure contaminated foods are not sold to consumers. In light of this, this study focused on mycotoxins that have been previously detected and commonly found in Africa and the possible means of their prevention or reduction of contamination to the barest minimum.

\section{MYCOTOXINS IN FOOD}

According to the FAO (7), approximately $25 \%$ of the world's agricultural products is contaminated with mycotoxins, and this contamination maybe due to saprophytic fungi before harvest of these crops while they are still in the field, during the process of harvest, and even after harvest during the storage of these products by endophytic fungi (8). This implies that mycotoxins are present all around, in stored food substances and ill-preserved food; when food substances are not well preserved, fungal growth may occur, leading to the production of mycotoxins. Moreover, mycotoxins can occur naturally (8), which makes it easier for them to exist in the human environments and make them unsafe. However, although many efforts have been made to completely eradicate mycotox- ins from food and agricultural products, these methods have not been proven to be completely effective. These methods may be physical, chemical, or biological detoxification strategies; furthermore, dietary strategies represent the most recent approaches to counteract the problem of mycotoxins (9).

Humans can be exposed to mycotoxin through the consumption of contaminated plant-derived foods, from the carry-over of mycotoxins and their metabolites to animal products such as meat and eggs (10), or from exposure to air and dust contaminated with toxins $(11,12)$. Exposure to these toxins is more likely to predominate in parts of the world where there are poor methods for the pest infestation control of crops, transportation facilities, and storage facilities; however, it can also be rampant in societies with a high level of poverty, where people consume only the available and not the preferable. Constant exposure to mycotoxins is also common where there are no rules and laws that protect the food intake of the populace. In developed countries, especially in subgroups in which poor food handling is common, there can be a risk of exposure to mycotoxins, making the populace vulnerable to mycotoxin-induced infections. However because mycotoxins are natural contaminants (13), their presence in food may be absolutely unavoidable.

According to John and Miller (14), mycotoxins have been the cause of epidemics in humans and animals for the last 30 years. Among these, the ergotism breakout in Europe led to hundreds of thousands of deaths in the last millennium. Mycotoxins were also the cause of alimentary toxic aleukia, which killed approximately a hundred thousand Russians between 1942 and 1948 (14). They have the ability to inflict many illnesses, such as headaches and various gastrointestinal illnesses including abdominal pain, vomiting, and diarrhea $(7,14)$. These toxins are known to be responsible for the death of millions of humans annually (15).

\section{TYPES OF MYCOTOXINS}

Aflatoxins. These are extremely toxic secondary metabolites of certain Aspergillus molds, such as Aspergillus flavus, Aspergillus parasiticus, and Aspergillus nomius $(16,17)$, which have been classified by the WHO as genotoxic and carcinogenic (7). When ingested, inhaled, or absorbed through the skin, aflatoxins have carcinogenic, hepatotoxic, teratogenic, and mutagenic effects on human health, even at very small concentrations $(6,15,17)$. They were shown to be the cause of Turkey $\mathrm{X}$ disease, i.e. hepatic necrosis, in 1960 (16). Aflatoxins were also the cause of aflatoxicosis that occurred in 1981, 2001, 2004, and 2005 in Kenya (Africa). According to Makun et al. (18), $\mathrm{AFB}_{1}$ is the most potent mycotoxin and is known to be hepatotoxic and hepatocarcinogenic. In 2004, aflatoxins were the cause of the death of 123 people in the eastern province of 
(A)

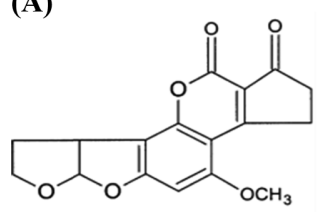

(B)

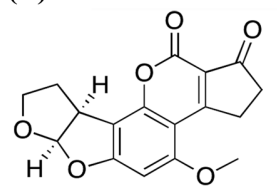

(C)

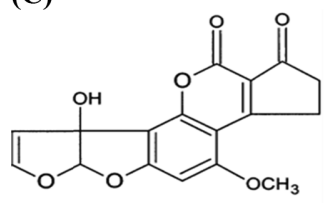

(E)

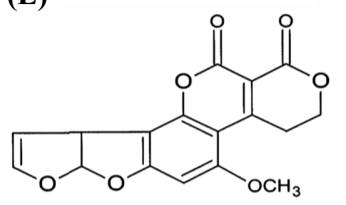

(D)

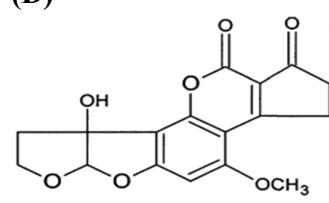

(F)

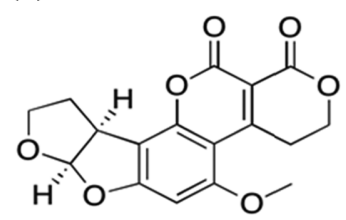

Fig. 1. Chemical structure of aflatoxin. (A) Aflatoxin $B_{1},(B)$ Aflatoxin $B_{2}$ (C) Aflatoxin $M_{1}$, (D) Aflatoxin $M_{2}$ (E) Aflatoxin $G_{1}$, (F) Aflatoxin $\mathrm{G}_{2}$.

Kenya (19). The exposure to $\mathrm{AFB}_{1}$ in conjunction with a low protein diet, as described in (20), caused a decrease in the weight gain and kidney dysfunction in rats.

Aflatoxins (AFs) are known to thrive in regions with high temperature and humidity, which are optimal for the growth of molds and the production of toxins (21-23). When aflatoxins are ingested, inhaled, or absorbed through the skin, they cause carcinogenic, hepatotoxic, teratogenic, and mutagenic effects in human and animals (rats, ferrets, ducks, trout, dogs, turkeys, cattle, and pigs), even at low concentrations $(6,15,17)$. According to Bilotti et al. (24), when pigs were exposed to aflatoxins, symptoms of thymic depression were observed, and decreased cellular immunity and T-cell function, when exposed to aflatoxins (24). The chemical structure of some aflatoxins are shown in Fig. 1.

Ochratoxins. Ochratoxins, produced by Penicillium, Fusarium, and Aspergillus species, are found naturally in various plant products such as cereals, coffee, beans, pulses, and dried fruits (25). It has been found in rice and maize samples obtained from west Africa, specifically Nigeria (26). Ochratoxin causes nephropathy in humans (27); it is also suspected to be the cause of Tunisian nephropathy and human Balkan endemic nephropathy (BEN) $(28,29)$. This mycotoxin is known for its teratogenic effect; it can cause an adverse effect on the fetus in the womb owing its ability to cross the placenta and cause the malformation of the central nervous system and damage to the brain (30). Darwish et al. (2) reported that ochratoxin toxicity was widespread in Africa.

Fumonisins. These are produced by various Fusarium species, including Fusarium verticillioides and Fusarium proliferatum (31). F. verticillioides, which is a major species of economic importance, grow as a corn endophyte in both vegetative and reproductive tissues, often without the appearance of disease symptoms in the plant. It is present in virtually all corn samples. It has been found in maize and corn samples from Nigeria and South Africa $(26,32)$. However, dependent on the weather conditions, insect damage, and the fungal and plant genotype, they can cause seedling blight, stalk rot, and ear rot (33). Fumonisin has been linked to cancer of the esophagus in humans (34), although it affects animals in different ways: it has been known to be the cause of various illnesses, such as leukoencephalomalacia in equines and rabbits $(31,35)$.

Zearalenone. Zearalenone is a secondary metabolite from Fusarium graminearum. It was found to be present in addition to other mycotoxins in samples of rice, maize, and peanuts obtained from Cote d'Ivoire, Africa (36). Zearalenone is biosynthesized through a polyketide pathway by $F$. graminearum, Fusarium culmorum, and Fusarium equiseti $(5,36)$. These species are known as regular contaminants of cereal crops worldwide (37). The consumption of zearalenone in small quantities has been proven to affect animal health, posing serious health threats and causing illnesses such as hyperestrogenic syndrome in pigs (38). When zearalenone is present in large quantities, it can cause disrupt conception, abortion, and other problems (38).

Trichothecenes. These are produced by several fungal genera, which include Fusarium, Trichoderma, Myrothecium, Trichothecium, Verticimonosporium, Stachybotrys, and Cephalosporium. Trichothecenes have been reported in Middle East Africa, where they were found to be present in feed and feed ingredients (39). They are a large group of mycotoxins that consist of more than 180 structurally related sesquiterpenoid mycotoxins produced from essential raw materials used in animal food and feeds such as maize, wheat, and oats $(13,39)$. They are known to be strong inhibitors of protein synthesis that can be absorbed into the body through the skin to inhibit protein synthesis in the body, harming the health of its host (13). Trichothecenes, such as other mycotoxins, are resistant to heat.

Patulin. Patulin is common in rotten apples, although it has been found in vegetables and other types of fruit, and has been detected in apple and apple products in South Africa $(40,41)$. It is produced specifically by Penicillium and Aspergillus (42), and is stable even at high temperatures; therefore, it cannot be eliminated by thermal denaturation. However, fermentation may reduce its stability (43). In 1998, Llewellyn et al. (44) reported that it can be destroyed by antioxidant and antimicrobial agents. 
Table 1. Health effects of common mycotoxins

\begin{tabular}{llc}
\hline \hline \multicolumn{1}{c}{ Mycotoxin } & \multicolumn{1}{c}{ Health effect } & Reference \\
\hline Aflatoxins & Hepatotoxic and immunosuppressive & 46 \\
Ochratoxin A & Carcinogenic, genotoxic, immunosuppressive, nephrotoxic and induction of upper urinary tract disease & 46,47 \\
Fumonisins & Carcinogenic, hepatotoxic, nephrotoxic, immunosuppressive & 48,49 \\
Deoxynivalenol & Nausea, vomiting, diarrhea, reproductive effects and toxicosis & 50,51 \\
Trichothecenes & Hepatotoxic, genotoxic, and immunosuppressive & 48,51 \\
Zearalenone & Carcinogenic, hormonal imbalance, and reproductive effects & 46,52 \\
Patulin & Neurologic and gastrointestinal & 5 \\
\hline
\end{tabular}

Patulin was previously been used as antibiotic against gram-positive and gram-negative bacteria, but was discovered to be toxic and therefore its use as an antibiotic has been discouraged (44). Patulin is used as a potassiumuptake inhibitor in the laboratory and it also induces erythrocyte death at physiological concentrations (45). The health effects of some mycotoxins are summarized in Table 1.

\section{MYCOTOXIN PREVENTION STRATEGIES}

The prevention and control of mycotoxins can be achieved by using mechanical, physical, chemical, and biological control strategies:

Mechanical control. This involves the prevention of mold and fungus growth in crops and foodstuffs, as well as the continuous surveillance of mycotoxin in agricultural crops and general products. According to Clara (53), the prevention of mycotoxin production in fungi from the field is usually considered the best approach to impede the harmful effects of mycotoxins on animals and human health. This can be achieved by sound agricultural practices that involve crop rotation techniques, cultivating and harvesting at the appropriate time and seasons/conditions, and the reduction of stress in the plants. Inoculum sources that can produce mycotoxins when decaying, such as weeds or agricultural residues, should be minimized to avoid contamination. According to Chang et al. (48), mechanical sorting implies that clean products are separated from moldy or infected products that may contain mycotoxins. Although the prevention of mycotoxin contamination in the field is strongly encouraged and offers the ideal approach to control mycotoxins (54), it may not be possible to achieve this completely. Therefore, postharvest strategies aimed at reducing the fungal contamination and, consequently, the mycotoxin content of agricultural products during storage, handling, processing, and transport must be put in place; this includes the improvement of drying and storage conditions, the use of chemical and natural agents, and irradiation (55).

Physical control. This involves thorough cleaning to remove general dirt and may also involve washing with sodium carbonate solution or water.

Research has shown that the exposure of food items to very high temperatures, of at least $150^{\circ} \mathrm{C}$, which is above cooking temperature, can reduce the mycotoxin content of food. Heat treatment is therefore another suggested technique; recently, Blanchard and Manderville (46) found a $84 \%$ loss of mycotoxins in food exposed to high temperature (approximately $150^{\circ} \mathrm{C}$ and above). However, food exposed to temperatures as high as those mentioned above might not be beneficial to the body owing to the loss of essential components and nutrients.

Other means include the reduction of the moisture content of plants and seeds after harvest and during storage, the use of fungicides and preservatives against fungal growth, the prevention of insect infestation in stored products, as well as the removal of contaminated seeds. Furthermore, Whitlow and Hager (37) suggested that insectresistant seeds, which can resist insect damage and also fungal disease, must be planted as this will prevent the contamination of crops by mycotoxins while they are still in the field. Whitlow and Hager (37) also reported that there should not be a delay in harvesting the crops, as this increases the chances of mycotoxin contamination. In addition, during harvest, he suggested that contact of the soil with agricultural products should be prevented, as this will also help to prevent the spread and contamination of these foods by mycotoxins. In addition, the storage location should be kept at temperatures at which mold does not grow.

Storage facilities should be sufficient to eliminate moisture migration, condensation, or leaks; grains stored for more than 14 days should be kept aerated and cool. This is important as aeration reduces the growth and spread of moulds that can cause contamination. In addition, Whitlow and Hager (37) also stated that storage facilities should always be checked for overheating and molding, as this should be prevented. The use of accepted and standard methods for making silage cannot be overemphasized; they should be followed strictly to ensure the output of non-contaminated foods.

Chemical approaches. Many chemicals have been found to be effective for the elimination of mycotoxins 
$(56,57)$; these include various acids, bases, salts, oxidizing agents, chlorinating/reducing agents, salts, and others, such as formaldehyde. Ammoniation is a widely-known method (58) that has received attention for the detoxification of aflatoxin- or ochratoxin-contaminated feeds and has been used successfully in several countries. It completely decomposes OTA in corn, wheat, and barley (59). Although the process does not lead to the formation and accumulation of toxic breakdown products of mycotoxins in agricultural products, it causes the observed changes in sensory and nutritional qualities, such as a brown color of the treated cereals and decreases in lysine and sulfur-containing amino acids.

Ammoniation is an approved procedure for the detoxification of aflatoxin-contaminated agricultural commodities and feed in some parts of the United States (60). In addition, in France and Senegal, ammoniation is used for mycotoxin detoxification in contaminated peanut, cotton, and maize meals (60). Alkaline hydrogen peroxide, sodium hydroxide, and monomethylamine or ammonium with calcium hydroxide treatments have also been found to be effective methods for OTA decontamination in this matrix (61). Recently, the control of fungi producing mycotoxin has been achieved by using plant extracts and essential oil (plant products) as fungicides (62).

In stored grains, chemicals such as sodium bisulfite, ozone, and ammonia can be used to prevent the growth of fungi and the biosynthesis of mycotoxins (58-63).

Microbiological methods. Microbes and their enzymes can be applied for mycotoxin detoxification. Several reports have described the OTA-degrading activities of the microbial flora of the mammalian gastrointestinal tract, including the rumen microbes of cows and sheep (64). In addition, numerous other bacteria, protozoa, and fungi were shown to be able to degrade OTA (48). It has been ascertained that lactic acid bacteria, propionic acid bacteria, and Bacillus sp. can inhibit the growth of fungi and mycotoxin production (65). Some enzymes, such as carboxypeptidase A (66) lipases from Aspergillus niger, and some commercial proteases (66) have also been identified as capable of performing this reaction.

\section{CONCLUSION AND RECOMMENDATION}

Mycotoxins are a threat to human health as they may cause severe and irrevocable damage to human health, such as cancer, in the developing nations of the world. It is known that almost nothing can be done to remove mycotoxins from food and feed once contaminated, because most mycotoxins are resistant to heat within the normal range of cooking temperatures. Therefore, the adequate prevention and control of these toxic substances in agricultural products while they are still on the field must be encouraged as this will drastically reduce the spread of mycotoxins and hence the reduction of various mycotoxininduced illnesses. This will also ensure food safety, as well as the long lifespan of the African populace. Governments and research organizations should therefore create policies that will help tackle the occurrence/prevalence of mycotoxins, as this will offer the best prospects for the successful development of sustainable food systems in Africa.

\section{ACKNOWLEDGMENTS}

The North west university, South Africa is appreciated for the financial support rendered.

\section{CONFLICT OF INTEREST}

The authors of this article hereby declare that there are no conflicts of interest.

Received March 22, 2018; Revised July 9, 2018; Accepted August 2, 2018

\section{REFERENCES}

1. Hussein, H.S. and Brasel, J.M. (2001) Toxicity, metabolism, and impact of mycotoxins on humans and animals. Toxicology, 167, 101-134.

2. Darwish, W.S., Ikenaka, Y., Nakayama, S.M.M. and Ishizuka, M. (2014) An overview on mycotoxin contamination of foods in Africa. J. Vet. Med. Sci., 76, 789-797.

3. World Health Organisation, International Agency for Research on Cancer (WHO-IARC) (1993) Tosins derived from Fusarium moniliforme: fumonisins $\mathrm{B}_{1}$ and $\mathrm{B}_{2}$, and fusarin C. IARC Monogr. Eval. Carcinog. Risks Hum., 56, 445-462.

4. Iheshiulor, O.O.M., Esonu, B.O., Chuwuka, O.K., Omede, A.A., Okoli, I.C. and Ogbuewu, I.P. (2011) Effects of mycotoxins in animal nutrition. Asian J. Anim. Sci., 5, 19-33.

5. Bennett, J.W. and Klich, M. (2003) Mycotoxins. Clin. Microbiol. Rev., 16, 497-516.

6. Zain, M.E. (2011) Impact of mycotoxins on humans and animals. J. Saudi Chem. Soc., 15, 129-144.

7. World Health Organization \& Food and Agriculture Organization of the United Nations (2011) FAO/WHO Guide for Application of Risk Analysis Principles and Procedures during Food Safety Emergencies, Food and Agriculture Organization of the United Nations, Rome.

8. Streit, E., Schatzmayr, G., Tassis, P., Tzika, E., Marin, D., Taranu, I., Tabuc, C., Nicolau, A., Aprodu, I., Puel, O. and Oswald, I.P. (2012) Current situation of mycotoxin contamination and co-occurrence in animal feed-focus on Europe. Toxins, 4, 788-809.

9. Kabak, B., Dobson, A.D. and Var, I. (2006) Strategies to prevent mycotoxin contamination of food and animal feed: a review. Crit. Rev. Food Sci. Nutr., 46, 593-619.

10. Bonel, L., Vidal, J.C., Duato, P. and Castillo, J.R. (2011) An electrochemical competitive biosensor for ochratoxin A 
based on a DNA biotinylated aptamer. Biosens. Bioelectron., 26, 3254- 3259.

11. Jarvis, B.B. (2002) Chemistry and toxicology of molds isolated from water-damaged buildings. Adv. Exp. Med. Biol., 504, 43-52.

12. Niculita-Hirzel, H., Hantier, G., Storti, F., Plateel, G. and Roger, T. (2016) Frequent occupational exposure to Fusarium mycotoxins of workers in the swiss grain industry. Toxins, 8, 370.

13. Zinedine, A. and Mañes, J. (2009) Occurrence and legislation of mycotoxins in food and feed from Morocco. Food Control, 20, 334-344.

14. John, I.P. and Miller, J.D. (2017) A conscise history of mycotoxin research. J. Agric. Food Chem., 65, 7021-7033.

15. Wen, J., Kong, W., Hu, Y., Wang, J. and Yang, M. (2014) Multi-mycotoxins analysis in ginger and related products by UHPLC-FLR detection and LC-MS/MS confirmation. Food Control, 43, 82-87.

16. Alcaide-Molina, M., Ruiz-Jiménez, J., Mata-Granados, J. and de Castro, M.L. (2009) High through-put aflatoxin determination in plant material by automated solid-phase extraction on-line coupled to laser-induced fluorescence screening and determination by liquid chromatography-triple quadrupole mass spectrometry. J. Chromatogr. A, 1216, $1115-1125$.

17. Ali, N., Hashim, N., Saad, B., Safan, K., Nakajima, M. and Yoshizawa, T. (2005) Evaluation of a method to determine the natural occurrence of aflatoxins in commercial traditional herbal medicines from Malaysia and Indonesia. Food Chem. Toxicol., 43, 1763-1772.

18. Makun, H.A., Dutton, M.F., Njobeh, P.B., Mwanza, M. and Kabiru, A.Y. (2011) Natural multi-occurrence of mycotoxins in rice from Niger State, Nigeria. Mycotoxin Res., 27, $97-$ 104.

19. Nyaga, P.N. (2010) Report on Aflatoxin contamination in Maize, Ministry of Agriculture.

20. Rotimi, O.A., Rotimi, S.O., Oluwafemi, F., Ademuyiwa, O. and Balogun, E.A. (2018) Oxidative stress in extrahepatic tissues of rats co-exposed to aflatoxin $\mathrm{B}_{1}$ and low protein diet. Toxicol. Res., 34, 211-220.

21. Ventura, M., Gomez, A., Anaya, I., Díaz, J., Broto, F., Agut, M. and Comellas, L. (2004) Determination of aflatoxins B1, G1, B2 and G2 in medicinal herbs by liquid chromatography-tandem mass spectrometry. J. Chromatogr. A, 1048, 2529.

22. Zöllner, P. and Mayer-Helm, B. (2006) Trace mycotoxin analysis in complex biological and food matrices by liquid chromatography-atmospheric pressure ionisation mass spectrometry. J. Chromatogr. A, 1136, 123-169.

23. Afsah-Hejri, L., Jinap, S., Hajeb, P., Radu, S. and Shakibazadeh, S. (2013) A review on mycotoxins in food and feed: Malaysia case study. Compr. Rev. Food Sci. Food Saf., 12, 629-651.

24. Bilotti, L.G., Fernández Pinto, V.E. and Vaamonde, G. (2000) Aflatoxin production in three selected samples of triticale, wheat and rye grown in Argentina. J. Sci. Food Agric., 80, 1981-1984.

25. Duarte, S., Pena, A. and Lino, C. (2010) A review on ochratoxin A occurrence and effects of processing of cereal and cereal derived food products. Food Microbiol., 27, 187-198.

26. Egbuta, M.A. (2012) Ochratoxins Occur Primarily in Cereals in Northern Europe and Africa. A Disseratation Submitted to the Faculty of Health Sciences, University of Johannesburg, South Africa.

27. Ribelin, W., Fukushima, K. and Still, P. (1978) The toxicity of ochratoxin to ruminants. Can. J. Comp. Med., 42, 172.

28. Hassan, A.M., Sheashaa, H.A., Fattah, M.F.A., Ibrahim, A.Z., Gaber, O.A. and Sobh, M.A. (2006) Study of ochratoxin $\mathrm{A}$ as an environmental risk that causes renal injury in breast-fed Egyptian infants. Pediatr. Nephrol., 21, 102-105.

29. Malir, F., Ostry, V., Pfohl-Leszkowicz, A. and Roubal, T. (2012) Ochratoxin A exposure biomarkers in the Czech Republic and comparison with foreign countries. Biomarkers, 17, 577-589.

30. Soleas, G.J., Yan, J. and Goldberg, D.M. (2001) Assay of ochratoxin A in wine and beer by high-pressure liquid chromatography photodiode array and gas chromatography mass selective detection. J. Agric. Food Chem., 49, 2733-2740.

31. Marasas, W. (2001) Discovery and occurrence of the fumonisins: a historical perspective. Environ. Health Perspect., 109, 239.

32. Edson, N., Bradley, C.F., Cees, W. and Altus, V. (2011) Fusarium spp. and levels of fumonisins in maize produced by subsistence farmers in South Africa. S. Afr. J. Sci., 107, 12.

33. Czembor, E., Adamczyk, J., Posta, K., Oldenburg, E. and Schürch, S. (2010) Prevention of ear rots due to Fusarium spp. on maize and mycotoxin accumulation in Food Quality and Safety, 6th framework programme, guide number 3.

34. Shephard, G. (2011) Fusarium mycotoxins and human health. Plant Breed. Seed Sci., 64, 113-121.

35. Giannitti, F., Diab, S.S., Pacin, A.M., Barrandeguy, M., Larrere, C., Ortega, J. and Uzal, F.A. (2011) Equine leukoencephalomalacia (ELEM) due to fumonisins B1 and B2 in Argentina. Pesq. Vet. Bras., 31, 407-412.

36. Sangare-Tigori, B., Moukha, S., Kouadio, H.J., Betbeder, A.M., Dano, D.S. and Creppy, E.E. (2006) Co-occurrence of aflatoxin $\mathrm{B}_{1}$, fumonisin $\mathrm{B}_{1}$, ochratoxin $\mathrm{A}$ and zearalenone in cereals and peanuts from Cote d'Ivoire. Food Addit. Contam., 23, 1000-1007.

37. Whitlow, L. and Hagler, W. (2004) Nutrional Biotechnology in the feed and food industries. Proceedings of All tech's 20th Annual Symposium: re-imagining the feed industry, Lexington, Kentucky, USA, 23-26 May 2004.

38. Reddy, K., Salleh, B., Saad, B., Abbas, H., Abel, C. and Shier, W. (2010) An overview of mycotoxin contamination in foods and its implications for human health. Toxin Rev., 29, 3-26.

39. Rodrigues, I., Handl, J. and Binder, E.M. (2011) Mycotoxin occurrence in commodities, feeds and feed ingredients sourced in the Middle East and Africa. Food Addit. Contam. Part B Surveill., 4, 168-179.

40. Shephard, G.S., Van der Westhuizen, L., Katerere, D.R., Herbst, M. and Pineiro, M. (2010) Preliminary exposure assessment of deoxynivalenol and patulin in South Africa. Mycotoxin Res., 26, 181-185.

41. Katerere, D.R., Stockenström, S., Thembo, K.M., Balducci, G. and Shephard, G.S. (2007) Investigation of patulin con- 
tamination in apple juice sold in retail outlets in Italy and South Africa. Food Addit. Contam., 24, 630-634.

42. Ismaiel, A.A. and Papenbrock, J. (2015) Mycotoxins: producing fungi and mechanisms of phytotoxicity. Agriculture, 5, $492-537$.

43. Junaid, S., Olarubofin, F. and Olabode, A. (2010) Mycotic contamination of stockfish sold in Jos, Nigeria. J. Yeast Fungal Res., 1, 136-141.

44. Llewellyn, G., McCay, J., Brown, R., Musgrove, D., Butterworth, L., Munson, A.E. and White, K.L., Jr. (1998) Immunological evaluation of the mycotoxin patulin in female B6C3F 1 mice. Food Chem. Toxicol., 36, 1107-1115.

45. Lupescu, A., Jilani, K., Zbidah, M. and Lang, F. (2013) Patulin-induced suicidal erythrocyte death. Cell. Physiol. Biochem., 32, 291-299.

46. Blanchard, D.J. and Manderville, R.A. (2016) An internal charge transfer-DNA platform for fluorescence sensing of divalent metal ions. ChemComm, 52, 9586-9588.

47. Faucet-Marquis, V., Joannis-Cassan, C., Hadjeba-Medjdoub, K., Ballet, N. and Pfohl-Leszkowicz, A. (2014) Development of an in vitro method for the prediction of mycotoxin binding on yeast-based products: case of aflatoxin B1, zearalenone and ochratoxin A. Appl. Microbiol. Biotechnol., 98, 7583-7596.

48. Chang, H., Li, P., Zhang, W., Liu, T., Hoffmann, A., Deng, L. and Wu, M. (2014) Nanometer-thick yttrium iron garnet films with extremely low damping. IEEE Magn. Lett., 5, 14.

49. Tian, Y., Tan, Y., Liu, N., Liao, Y., Sun, C., Wang, S. and Wu, A. (2016) Functional agents to biologically control deoxynivalenol contamination in cereal grains. Front. Microbiol., 7, 395.

50. Pinton, P. and Oswald, I.P. (2014) Effect of deoxynivalenol and other Type B trichothecenes on the intestine: a review. Toxins, 6, 1615-1643.

51. Ali, E.M. (2013) Phytochemical composition, antifungal, antiaflatoxigenic, antioxidant, and anticancer activities of Glycyrrhiza glabra L. and Matricaria chamomilla L. essential oils. J. Med. Plants Res., 7, 2197-2207.

52. Reddy, K., Nurdijati, S. and Salleh, B. (2010) An overview of plant-derived products on control of mycotoxigenic fungi and mycotoxins. Asian J. Plant Sci., 9, 126.

53. Asao, T., Buchi, G., Abdel-Kader, M., Chang, S., Wick, E.L. and Wogan, G. (1963) Aflatoxins B and G. J. Am. Chem. Soc., 85, 1706-1707.

54. Merrill, A.H., Jr., Sullards, M.C., Wang, E., Voss, K.A. and
Riley, R.T. (2001) Sphingolipid metabolism: roles in signal transduction and disruption by fumonisins. Environ. Health Perspect., 109, 283.

55. Shephard, G. (2008) Impact of mycotoxins on human health in developing countries. Food Addit. Contam. Part A Chem. Anal. Control Expo. Risk Assess., 25, 146-151.

56. Carvajal-Moreno, M. (2015) Metabolic Changes of Aflatoxin B1 to become an active carcinogen and the control of this toxin. Immunome Res., 11, 1.

57. Clara, C. (2013) Antifungal Secondary Metabolites from Monanthotaxis Littoralis with Activity against Mycotoxigenic Fungi from Maize, Egerton University.

58. Allameh, A., Rasooli, I. and Ziglari, T. (2011) Phytoinhibition of Growth and Aflatoxin Biosynthesis in Toxigenic Fungi, INTECH Open Access Publisher.

59. Nathanail, A.V., Syvähuoko, J., Malachová, A., Jestoi, M., Varga, E., Michlmayr, H., Adam, G., Sieviläinen, E., Berthiller, F. and Peltonen, K. (2015) Simultaneous determination of major type $\mathrm{A}$ and $\mathrm{B}$ trichothecenes, zearalenone and certain modified metabolites in Finnish cereal grains with a novel liquid chromatography-tandem mass spectrometric method. Anal. Bioanal. Chem., 407, 4745-4755.

60. Douglas, L.P. and William, D.P. (2001) Reduction of aflatoxin hazards using ammoniation. Rev. Environ. Contam. Toxicol., 171, 139-175.

61. Janos, V., Sandor, K., Zsanett, P., Csaba, V. and Beata, T. (2010) Chemical, physical and biological approaches to prevent ochratoxin induced toxicoses in humans and animals. Toxins, 2, 1718-1750.

62. Choudhary, A.K. and Kumari, P. (2010) Management of mycotoxin contamination in preharvest and post harvest crops: present status and future prospects. J. Phytol., 2, 3752.

63. Suttajit, M. (1989) Prevention and control of mycotoxins in Mycotoxin Prevention and Control in Foodgrains (Semple, R.L., Frio, A.S., Hicks, P.A. and Lozare, J.V. Eds.). Bankok, Thailand.

64. Rodrigues, I. (2014) A review on the effects of mycotoxins in dairy ruminants. Animal Prod. Sci., 54, 1155-1165.

65. Bunaciu, A.A., Aboul-Enein, H.Y. and Hoang, V.D. (2015) Raman spectroscopy for protein analysis. Appl. Spectrosc. Rev., 50, 377-386.

66. Abrunhosa, L., Paterson, R.R. and Venâncio, A. (2010) Biodegradation of ochratoxin A for food and feed decontamination. Toxins, 2, 1078-1079. 